\title{
APLIKASI METODE FUZZY MADM TOPSIS DALAM MENGANALISIS KEPUASAN PELANGGAN TERHADAP KUALITAS PELAYANAN PERUSAHAAN DAERAH AIR MINUM TIRTANADI BELAWAN
}

\author{
Dernawati Lubis ${ }^{1}$ dan Abil Mansyur ${ }^{2}$ \\ Program Studi Matematika \\ Fakultas Matematika dan Ilmu Pengetahuan Alam \\ Jl. Willem Isakandar Psr V Kotak Pos No. 1589 Medan 20221 \\ Email : $\underline{\text { dernawatilubis@ yahoo.co.id }}{ }^{1}$
}

\begin{abstract}
The quality and quantity of both ground and surface water in Belawan Area have deteriorated in the recent years. Despite of the loss, this could become opportunities for PDAM to get customers since there are not many choices left for the community. High economic growth allows the rising of community's willingness to pay, especially for basic needs such as water. As a consequence of the increasing customers, PDAM has to maintain its services. Evaluation and customer satisfaction's analysis are absolutely needed to be held regularly. Through this evaluation, PDAM will be able to arrange some strategies to maintain its existing customers and at the same time trying to draw more new customers. In this research, data analysis will employ Fuzzy MADM TOPSIS Method using structured questionnaire. The intended result of the study has a conclution that the customer satisfaction of the service quality PDAM Tirtanadi Belawan have gratified because the highest preference value that gratified alternative has 0.8194 . From the $14^{\text {th }}$ criteria of customer satisfaction that very gratifying is the courtesy, service security, that gratified is the service procedure, service conditions, clarity service, ability, justice, expense equity, expense certainty, environment freshmen, that enough gratify is discipline, responsibility, service speed, schedule certainty. The quality of service PDAM Tirtanadi Belawan is good.
\end{abstract}

Keywords: Fuzzy MADM TOPSIS Method, Customer satisfaction, Service Quality. 


\section{Pendahuluan}

Kebutuhan air bersih di Kecamatan Medan Belawan sebagian besar diperoleh dari PDAM Tirtanadi Belawan. Pelanggan PDAM Tirtanadi Belawan secara umum terdiri dari semua lapisan masyarakat. Namun pada kenyataan, sebagian besar pelanggan masih mengeluh tentang kualitas pelayanan yang diberikan oleh PDAM Tirtanadi Belawan. Dalam mengambil keputusan mengenai tingkat kepuasan pelanggan dan kualitas pelayanan perlu menggunakan suatu metode untuk pengambil keputusan dari multi kriteria untuk mengetahui tingkat kepuasan dan kualitas pelayanan yang diberikan oleh PDAM Tirtanadi untuk setiap pelanggannya. Untuk itu digunakanlah metode fuzzy Multi Attribute Decision Making Technique for Order Prefence by Similarity to Ideal Solution atau disebut fuzzy MADM TOPSIS. Metode TOPSIS lebih tepat digunakan untuk menyelesaikan permasalahan multi kriteria seperti pada pengukuran tingkat kepuasan dan kualitas pelayanan, dengan banyak kriteria sebagai komponen penilaian untuk setiap alternatif [1].

\section{Landasan Teori}

Kualitas pelayanan dapat diartikan sebagai upaya pemenuhan kebutuhan dan keinginan pelanggan serta ketepatan penyampaiannya dalam mengimbangi harapan pelanggan [2]. Kepuasan pelanggan adalah suatu perasaan senang yang langsung dirasakan oleh pelanggan ketika harapan pelanggan terhadap suatu produk atau jasa terpenuhi atau bahkan melampaui harapan pelanggan.

Indikator kepuasan pelanggan menurut Mahmudi (dalam [3]), meliputi :

1. Prosedur pelayanan

Kemudahan tahapan pelayanan yang diberikan kepada pelanggan dilihat dari sisi kesederhanaan alur pelayanan.

2. Persyaratan pelayanan

Persyaratan teknis dan administratif yang dibutuhkan untuk mendapatkan pelayanan sesuai dengan jenis pelayanannya. 
3. Kejelasan petugas pelayanan

Kejelasan dalam berkomunikasi dan kepastian informasi yang diberikan secara akurat.

4. Kedisiplinan petugas pelayanan

Kesungguhan petugas dalam memberikan pelayanan terutama terhadap konsistensi waktu kerja sesuai ketentuan yang berlaku.

5. Tanggung jawab petugas pelayanan

Kejelasan wewenang dan tanggung jawab petugas dalam memberikan produk yang berkualitas dan penyelesaian pelayanan yang baik.

6. Kemampuan petugas pelayanan

Tingkat keahlian dan ketrampilan yang dimiliki petugas dalam memberikan / menyelesaikan pelayanan kepada pelanggan.

7. Kecepatan pelayanan

Target waktu pelayanan dapat diselesaikan dalam waktu yang telah ditentukan oleh unit penyelenggara pelayanan.

8. Keadilan pelayanan

Pelaksanaan pelayanan dengan tidak membedakan golongan/status masyarakat yang dilayani.

9. Kesopanan petugas pelayanan

Sikap dan perilaku petugas dalam memberikan pelayanan kepada pelanggan secara sopan dan ramah serta saling menghargai dan menghormati.

10. Kewajaran biaya pelayanan

Keterjangkauan pelanggan terhadap besarnya biaya yang ditetapkan oleh unit pelayanan.

11. Kepastian biaya pelayanan

Kesesuaian antara biaya yang dibayarkan dengan biaya yang telah ditetapkan.

12. Kepastian jadwal pelayanan

Pelaksanaan waktu pelayanan sesuai dengan ketentuan yang telah ditetapkan.

13. Kenyamanan lingkungan

Kondisi sarana dan prasarana pelayanan yang bersih, rapi, dan teratur sehingga dapat memberikan rasa nyaman kepada penerima pelayanan.

14. Keamanan pelayanan 
Terjaminnya tingkat keamanan pelayanan ataupun sarana yang digunakan, sehingga pelanggan merasa tenang untuk mendapatkan pelayanan dan tidak boleh terjadi intimidasi atau tekanan kepada pelanggan dalam pelayanan.

Fuzzy Multiple Attribute Decision Making adalah suatu metode yang digunakan untuk menyeleksi alternatif dengan atribut (kriteria) dengan ciri-ciri terbaik dan mengklasifikasi alternatif berdasarkan peran tertentu.

Untuk menyelesaikan masalah FMADM, dibutuhkan 2 tahap, yaitu :

a. Membuat rating pada setiap alternatif berdasarkan agregasi derajat kecocokan pada semua kriteria.

b. Menguraikan metode TOPSIS untuk merangking semua alternatif untuk mendapatkan alternatif terbaik.

\section{TOPSIS (Technique For Order Preference By Similarity To Ideal} Solution) adalah salah satu metode pengambil keputusan multikriteria yang berfungsi sebagai peranking alternatif yang pertama kali diperkenalkan oleh Yoon dan Hwang tahun 1981.[4].

Secara umum, prosedur TOPSIS mengikuti langkah-langkah sebagai berikut:

1. Membuat matriks keputusan yang ternormalisasi $(R)$.

Matriks keputusan adalah struktur keputusan yang terdiri atas kolom dan baris tabel yang digunakan untuk pengambilan keputusan. Baris pada tabel ini akan menampilkan sejumlah alternatif keputusan atau solusi untuk menyelesaikan suatu masalah kualitas dan kolom pada tabel ini akan menampilkan kriteria penilaian diantara berbagai keputusan tersebut [5]. Matriks keputusan ternormalisasi adalah struktur keputusan yang terdiri atas kolom dan baris tabel yang tidak memiliki kriteria yang berulang dan sudah dikelompokkan dengan baik [6]. Untuk menentukan nilai elemen matriks keputusan yang ternormalisasi $\left(r_{i j}\right)$ dapat dilakukan dengan formula sebagai berikut :

$$
\begin{aligned}
& r_{i j}=\frac{x_{i j}}{\sqrt{\sum_{i=1}^{m} x_{i j}^{2}}} ; \text { dengan } i=1,2, \ldots, m \text { dan } \\
& j=1,2, \ldots, n
\end{aligned}
$$


2. Membuat matriks keputusan yang ternormalisasi terbobot $(Y)$.

Matriks keputusan yang ternormalisasi terbobot adalah pemberian pembobotan atau nilai bobot terhadap baris dan kolom yang sudah dikelompokkan dengan baik pada struktur keputusan (Wirodikro, 2009). [7]. Untuk menentukan nilai elemen matriks keputusan yang ternormalisasi terbobot $\left(y_{i j}\right)$ dapat dilakukan dengan formula sebagai berikut:

$$
y_{i j}=w_{j} r_{i j} ; \quad \text { dengan } i=1,2, \ldots, m \text { dan } j=1,2, \ldots, n
$$

Nilai $w_{j}$ diperoleh dari bobot preferensi pengambil keputusan, yaitu $w_{j}=\frac{\left(5 \times x_{1 j}\right)+\left(4 \times x_{2 j}\right)+\left(3 \times x_{3 j}\right)+\left(2 \times x_{4 j}\right)+\left(1 \times x_{5 j}\right)}{100}$

3. Menentukan matriks solusi ideal positif dan matriks solusi ideal negatif.

Solusi ideal positif adalah seluruh nilai terbaik yang dapat dicapai untuk setiap kriteria, dapat ditentukan berdasarkan ranking bobot. Solusi ideal negatif adalah seluruh nilai terburuk yang dapat dicapai untuk setiap kriteria, dapat ditentukan berdasarkan ranking bobot [8]. Matriks solusi ideal positif adalah suatu susunan bilangan nilai terbaik yang dapat dicapai untuk setiap kriteria yang diatur dalam baris dan kolom. Nilai terbaik adalah nilai terbesar dari alternatif untuk setiap kriteria.Matriks solusi ideal negatif adalah suatu susunan bilangan nilai terburuk yang dapat dicapai untuk setiap kriteria yang diatur dalam baris dan kolom. Nilai terburuk adalah nilai terkecil dari alternatif untuk setiap kriteria [9].

Untuk menentukan nilai elemen matriks solusi ideal positif $A^{+}$dan solusi ideal negatif $A^{-}$dapat ditentukan berdasarkan rating bobot ternormalisasi $\left(y_{i j}\right)$ sebagai:

$$
\begin{aligned}
& A^{+}=\left(y_{1}^{+}, y_{2}^{+}, \ldots, y_{n}^{+}\right) \\
& A^{-}=\left(y_{1}^{-}, y_{2}^{-}, \ldots, y_{n}^{-}\right)
\end{aligned}
$$

4. Menentukan jarak antara nilai setiap alternatif dengan matriks solusi ideal positif dan matriks solusi ideal negatif.

Untuk menentukan jarak antara alternatif $A_{i}$ dengan solusi ideal positif dapat dilakukan dengan formula sebagai berikut : 


$$
D_{i}^{+}=\sqrt{\sum_{j=1}^{n}\left(y_{j}^{+}-y_{i j}\right)^{2}} ; i=1,2, \ldots, m
$$

Untuk menentukan jarak antara alternatif $A_{i}$ dengan solusi ideal negatif dapat dilakukan dengan formula sebagai berikut :

$$
D_{i}^{-}=\sqrt{\sum_{j=1}^{n}\left(y_{i j}-y_{j}^{-}\right)^{2}} ; i=1,2, \ldots, m
$$

5. Menentukan nilai preferensi untuk setiap alternatif.

Untuk menentukan nilai preferensi untuk setiap alternatif $\left(V_{i}\right)$ dilakukan dengan formula sebagai berikut :

$$
V_{i}=\frac{D_{i}^{-}}{D_{i}^{-}+D_{i}^{+}} \quad ; i=1,2, \ldots, m
$$

Setelah nilai $V_{i}$ diperoleh, selanjutnya nilai $V_{i}$ diranking dari yang terbesar hingga yang terkecil. Nilai $V_{i}$ yang terbesar adalah nilai yang terpilih, dalam arti bahwa alternatif $A_{i}$ lah yang merupakan alternatif terbaik [4], [10].

\section{Metode Penelitian}

Langkah-langkah yang dilakukan dalam penelitian ini adalah :

A. Menentukan Variabel

B. Pengumpulan Data

Data yang diperoleh langsung dari pelanggan dengan melakukan survey dengan menyebarkan angket/kuisioner kepada pelanggan PDAM Tirtanadi Belawan.

C. Pengolahan Data

Dalam pengolahan data, langkah-langkah yang dilakukan adalah :

a. Membuat data rekapitulasi

b. Membuat nilai rata-rata data rekapitulasi

c. Membuat data awal kuesioner kepuasan pelanggan

d. Membuat rating pada setiap alternatif berdasarkan agregasi derajat kecocokan pada semua kriteria. 
e. Menguraikan metode TOPSIS untuk merangking semua alternatif untuk mendapatkan alternatif terbaik dengan cara :

1. Membuat matriks keputusan yang ternormalisasi

2. Membuat matriks keputusan yang ternormalisasi terbobot

3. Menentukan matriks solusi ideal positif dan matriks solusi ideal negatif

4. Menentukan jarak antara nilai setiap alternatif dengan matriks solusi ideal positif dan matriks solusi ideal negatif

5. Menentukan nilai preferensi untuk setiap alternatif dan meranking semua alternatif untuk mendapatkan alternatif terbaik

D. Penarikan Kesimpulan

Dari pengolahan data dengan menggunakan metode Fuzzy MADM TOPSIS, maka dapatlah diketahui tingkat kepuasan pelanggan terhadap kualitas pelayanan PDAM Tirtanadi Belawan dan kualitas pelayanan PDAM Tirtanadi Belawan yang sesungguhnya.

\section{Pembahasan}

Dalam penelitian ini variabel yang digunakan adalah $A$ dan $C$, dimana $A$ adalah alternatif dan $C$ adalah kriteria. Alternatif dalam hal ini adalah sangat memuaskan $\left(A_{1}\right)$, memuaskan $\left(A_{2}\right)$, cukup memuaskan $\left(A_{3}\right)$, tidak memuaskan $\left(A_{4}\right)$, sangat tidak memuaskan $\left(A_{5}\right)$ dan kriterianya adalah prosedur pelayanan $\left(C_{1}\right)$, persyaratan pelayanan $\left(C_{2}\right)$, kejelasan petugas pelayanan $\left(C_{3}\right)$, kedisiplinan petugas pelayanan $\left(C_{4}\right)$, tanggung jawab petugas pelayanan $\left(C_{5}\right)$, kemampuan petugas pelayanan $\left(C_{6}\right)$, kecepatan pelayanan $\left(C_{7}\right)$, keadilan pelayanan $\left(C_{8}\right)$, kesopanan petugas pelayanan $\left(C_{9}\right)$, kewajaran biaya pelayanan $\left(C_{10}\right)$, kepastian biaya pelayanan $\left(C_{11}\right)$, kepastian jadwal pelayanan $\left(C_{12}\right)$, kenyamanan lingkungan $\left(C_{13}\right)$, dan keamanan pelayanan $\left(C_{14}\right)$.

Untuk menyelesaikan masalah FMADM, dibutuhkan 2 tahap, yaitu :

a. Membuat rating pada setiap alternatif berdasarkan agregasi derajat kecocokan pada semua kriteria. 
Tabel 1 Rating Kecocokan Dari Setiap Alternatif Pada Setiap Kriteria

\begin{tabular}{|c|c|c|c|c|c|c|c|c|c|c|c|c|c|c|}
\hline Alternatif & $C_{1}$ & $C_{2}$ & $C_{3}$ & $C_{4}$ & $C_{5}$ & $C_{6}$ & $C_{7}$ & $C_{8}$ & $C_{9}$ & $C_{10}$ & $C_{11}$ & $C_{12}$ & $C_{13}$ & $C_{14}$ \\
\hline$A_{1}$ & 11 & 8 & 26 & 5 & 3 & 7 & 6 & 21 & 45 & 7 & 13 & 6 & 12 & 28 \\
\hline$A_{2}$ & 51 & 48 & 43 & 25 & 19 & 30 & 24 & 48 & 38 & 47 & 51 & 24 & 45 & 54 \\
\hline$A_{3}$ & 25 & 29 & 18 & 36 & 42 & 31 & 35 & 11 & 13 & 32 & 23 & 41 & 30 & 13 \\
\hline$A_{4}$ & 11 & 13 & 9 & 22 & 24 & 24 & 25 & 11 & 2 & 13 & 12 & 17 & 9 & 4 \\
\hline$A_{5}$ & 2 & 2 & 4 & 12 & 12 & 8 & 10 & 9 & 2 & 1 & 1 & 12 & 4 & 1 \\
\hline Jumlah & 100 & 100 & 100 & 100 & 100 & 100 & 100 & 100 & 100 & 100 & 100 & 100 & 100 & 100 \\
\hline
\end{tabular}

b. Menguraikan metode TOPSIS untuk merangking semua alternatif untuk mendapatkan alternatif terbaik dengan cara :

1. Membuat matriks keputusan yang ternormalisasi

Tabel 2 Membuat matriks keputusan yang ternormalisasi

\begin{tabular}{|c|c|c|c|c|c|c|c|c|c|c|c|c|c|c|}
\hline Alternatif & $C_{1}$ & $C_{2}$ & $C_{3}$ & $C_{4}$ & $C_{5}$ & $C_{6}$ & $C_{7}$ & $C_{8}$ & $C_{9}$ & $C_{10}$ & $C_{11}$ & $C_{12}$ & $C_{13}$ & $C_{14}$ \\
\hline$A_{1}$ & 0.1867 & 0.1376 & 0.479 & 0.0986 & 0.0562 & 0.1386 & 0.1185 & 0.3791 & 0.7453 & 0.1191 & 0.2215 & 0.1149 & 0.2133 & 0.4492 \\
\hline$A_{2}$ & 0.8655 & 0.8254 & 0.7922 & 0.4928 & 0.3557 & 0.5941 & 0.4742 & 0.8666 & 0.6293 & 0.7999 & 0.869 & 0.4597 & 0.7998 & 0.8662 \\
\hline$A_{3}$ & 0.4243 & 0.4987 & 0.3316 & 0.7096 & 0.7862 & 0.6139 & 0.6915 & 0.1986 & 0.2153 & 0.5446 & 0.3919 & 0.7853 & 0.5332 & 0.2085 \\
\hline$A_{4}$ & 0.1867 & 0.2235 & 0.1658 & 0.4336 & 0.4492 & 0.4753 & 0.4939 & 0.1986 & 0.0331 & 0.2213 & 0.2045 & 0.3256 & 0.1600 & 0.0642 \\
\hline$A_{5}$ & 0.0339 & 0.0344 & 0.0737 & 0.2365 & 0.2246 & 0.1584 & 0.1976 & 0.1625 & 0.0331 & 0.0170 & 0.0170 & 0.2298 & 0.0711 & 0.0160 \\
\hline
\end{tabular}

2. Membuat matriks keputusan yang ternormalisasi terbobot

Tabel 3 Bobot Kriteria

\begin{tabular}{|c|c|c|c|c|c|c|c|c|c|c|c|c|c|}
\hline$w_{1}$ & $w_{2}$ & $w_{3}$ & $w_{4}$ & $w_{5}$ & $w_{6}$ & $w_{7}$ & $w_{8}$ & $w_{9}$ & $w_{10}$ & $w_{11}$ & $w_{12}$ & $w_{13}$ & $w_{14}$ \\
\hline 4 & 4 & 4 & 3 & 3 & 4 & 3 & 4 & 5 & 4 & 4 & 3 & 4 & 5 \\
\hline
\end{tabular}

Tabel 4 Matriks Keputusan Ternormalisasi Terbobot

\begin{tabular}{|c|c|c|c|c|c|c|c|c|c|c|c|c|c|c|}
\hline Alternatif & $C_{1}$ & $C_{2}$ & $C_{3}$ & $C_{4}$ & $C_{5}$ & $C_{6}$ & $C_{7}$ & $C_{8}$ & $C_{9}$ & $C_{10}$ & $C_{11}$ & $C_{12}$ & $C_{13}$ & $C_{14}$ \\
\hline$A_{1}$ & 0.7467 & 0.5503 & 1.9161 & 0.2957 & 0.1685 & 0.5545 & 0.3556 & 1.5165 & 3.7263 & 0.4766 & 0.8861 & 0.3448 & 0.8531 & 2.2458 \\
\hline$A_{2}$ & 3.4621 & 3.3015 & 3.1689 & 1.4783 & 1.067 & 2.3764 & 1.4225 & 3.4664 & 3.1466 & 3.1998 & 3.4762 & 1.379 & 3.199 & 4.3312 \\
\hline$A_{3}$ & 1.6971 & 1.9947 & 1.3265 & 2.1287 & 2.3585 & 2.4556 & 2.0744 & 0.7944 & 1.0765 & 2.1786 & 1.5677 & 2.3558 & 2.1327 & 1.0427 \\
\hline$A_{4}$ & 0.7467 & 0.8942 & 0.6633 & 1.3009 & 1.3477 & 1.9011 & 1.4817 & 0.7944 & 0.1656 & 0.8851 & 0.8179 & 0.9768 & 0.6398 & 0.3208 \\
\hline$A_{5}$ & 0.1358 & 0.1376 & 0.2948 & 0.7096 & 0.6739 & 0.6337 & 0.5927 & 0.6499 & 0.1656 & 0.0681 & 0.0682 & 0.6895 & 0.2844 & 0.0802 \\
\hline
\end{tabular}

3. Menentukan matriks solusi ideal positif dan matriks solusi ideal negatif 
KARISMATIKA

VOL. 3 NO. 2 AGUSTUS 2017
ISSN : $2443-0366$

ISSN : 2528 -- 0279

Tabel 5 Matriks Solusi Ideal Positif dan Matriks Solusi Ideal Negatif

\begin{tabular}{|c|c|c|c|c|c|c|c|c|c|c|c|c|c|}
\hline$y_{1}^{+}$ & $y_{2}^{+}$ & $y_{3}^{+}$ & $y_{4}^{+}$ & $y_{5}^{+}$ & $y_{6}^{+}$ & $y_{7}^{+}$ & $y_{8}^{+}$ & $y_{9}^{+}$ & $y_{10}^{+}$ & $y_{11}^{+}$ & $y_{12}^{+}$ & $y_{13}^{+}$ & $y_{14}^{+}$ \\
\hline 3.4621 & 3.3015 & 3.1689 & 2.1287 & 2.3585 & 2.4556 & 2.0744 & 3.4664 & 3.7263 & 3.1998 & 3.4762 & 2.3558 & 2.1327 & 4.3312 \\
\hline
\end{tabular}

\begin{tabular}{|c|c|c|c|c|c|c|c|c|c|c|c|c|c|}
\hline$y_{1}^{-}$ & $y_{2}^{-}$ & $y_{3}^{-}$ & $y_{4}^{-}$ & $y_{5}^{-}$ & $y_{6}^{-}$ & $y_{7}^{-}$ & $y_{8}^{-}$ & $y_{9}^{-}$ & $y_{10}^{-}$ & $y_{11}^{-}$ & $y_{12}^{-}$ & $y_{13}^{-}$ & $y_{14}^{-}$ \\
\hline 0.1358 & 0.1376 & 0.2948 & 0.2957 & 0.1685 & 0.5545 & 0.3556 & 0.6499 & 0.1656 & 0.0681 & 0.0682 & 0.3448 & 0.2844 & 0.0802 \\
\hline
\end{tabular}

4. Menentukan jarak antara nilai setiap alternatif dengan matriks solusi ideal positif dan matriks solusi ideal negatif

Tabel 6 Jarak Antara Nilai Setiap Alternatif Dengan Matriks Solusi Ideal Positif Dan Matriks Solusi Ideal Negatif.

\begin{tabular}{|l|l|}
\hline$D_{1}^{+}$ & 7.6938 \\
\hline$D_{2}^{+}$ & 2.2248 \\
\hline$D_{3}^{+}$ & 6.1545 \\
\hline$D_{4}^{+}$ & 8.6179 \\
\hline$D_{5}^{+}$ & 10.296 \\
\hline
\end{tabular}

dan

\begin{tabular}{|c|c|}
\hline$D_{1}^{-}$ & 4.7382 \\
\hline$D_{2}^{-}$ & 10.093 \\
\hline$D_{3}^{-}$ & 6.1331 \\
\hline$D_{4}^{-}$ & 2.8979 \\
\hline$D_{5}^{-}$ & 0.7797 \\
\hline
\end{tabular}

5. Menentukan nilai preferensi untuk setiap alternatif dan meranking semua alternatif untuk mendapatkan alternatif terbaik

Tabel 7 Nilai Preferensi Untuk Setiap Alternatif

\begin{tabular}{|c|c|c|c|}
\hline$V_{i}$ & Nilai Preferensi & Alternatif & Ranking \\
\hline$V_{1}$ & 0.3811 & Sangat memuaskan $\left(A_{1}\right)$ & 3 \\
\hline$V_{2}$ & 0.8194 & Memuaskan $\left(A_{2}\right)$ & 1 \\
\hline$V_{3}$ & 0.4991 & Cukup Memuaskan $\left(A_{3}\right)$ & 2 \\
\hline$V_{4}$ & 0.2516 & Tidak Memuaskan $\left(A_{4}\right)$ & 4 \\
\hline$V_{5}$ & 0.0704 & Sangat Tidak Memuaskan $\left(A_{5}\right)$ & 5 \\
\hline
\end{tabular}


Dari nilai $V_{i}$ pada Tabel 4.7 dapat dilihat bahwa $V_{2}$ (nilai preferensi untuk $A_{2}$ ) adalah nilai terbesar dengan ranking pertama yaitu 0.8194, sehingga dapat disimpulkan bahwa alternatif kedua $\left(A_{2}\right)$ yang akan lebih dipilih karena merupakan alternatif terbaik dengan peringkat pertama. Dengan kata lain, tingkat kepuasan pelanggan terhadap kualitas pelayanan Perusahaan Daerah Air Minum Tirtanadi Belawan adalah Memuaskan.

\section{Kesimpulan}

Berdasarkan hasil penelitian yang telah dilakukan dapat disimpulkan sebagai berikut:

1. Tingkat kepuasan pelanggan terhadap kualitas pelayanan Perusahaan

Daerah Air Minum Tirtanadi Belawan adalah memuaskan dengan nilai preferensi 0.8194, dari 14 kriteria kepuasan pelanggan yang sangat memuaskan adalah Kesopanan Petugas Pelayanan $\left(C_{9}\right)$, Keamanan Pelayanan $\left(C_{14}\right)$, yang memuaskan adalah Prosedur Pelayanan $\left(C_{1}\right)$, Persyaratan Pelayanan $\left(C_{2}\right)$, Kejelasan Petugas Pelayanan $\left(C_{3}\right)$, Kemampuan Petugas Pelayanan $\left(C_{6}\right)$, Keadilan Pelayanan $\left(C_{8}\right)$, Kewajaran Biaya Pelayanan $\left(C_{10}\right)$, Kepastian Biaya Pelayanan $\left(C_{11}\right)$, dan Kenyamanan Lingkungan $\left(C_{13}\right)$, yang cukup memuaskan adalah Kedisiplinan Petugas Pelayanan $\left(C_{4}\right)$, Tanggung Jawab Petugas Pelayanan $\left(C_{5}\right)$, Kecepatan Pelayanan $\left(C_{7}\right)$, dan Kepastian Jadwal Pelayanan $\left(C_{12}\right)$.

2. Kualitas pelayanan Perusahaan Daerah Air Minum Tirtanadi Belawan dapat diukur dari tingkat kepuasan pelanggan, yaitu Berkualitas atau Baik.

\section{DAFTAR PUSTAKA}

[1] Kasanah, S. (2009). Aplikasi Fuzzy MADM Metode TOPSIS untuk Identifikasi Servqual. Jurnal, Fakultas Sains dan Teknologi, UIN Malang: Malang.

[2] Tjiptono, F. (1997). Prinsip-Prinsip Total Quality Service. Andi Offset : Yogyakarta

[3] Fardhani, H. (2007). Analisis Faktor-Faktor yang Mempengaruhi Kepuasan Masyarakat pada Pelayanan Perijinan Terpadu: Diponegoro. 
[4] Kusumadewi, S., Hartati, S., Harjoko, A., dan Wardoyo, R. (2006). Fuzzy Multi-Attribute Decision Making (Fuzzy MADM). Graha Ilmu : Yogyakarta

[5] Al-Assaf, A. F. (2009). Mutu Pelayanan Kesehatan Perspektif Internasional. Cetakan Pertama. Penerbit Buku Kedokteran EGC: Jakarta.

[6] Kadir, A. (2008). Konsep dan Tuntunan Praktis Basis Data. Penerbit Erlangga : Jakarta.

[7] Lestari, S. (2011). Seleksi Penerimaan Calon Karyawan Menggunakan Medode TOPSIS. Konferensi Nasional Sistem dan Informatika, IBI Darmajaya: Bali.

[8] Tampomas, H. (2003). Matriks. Penerbit Gramedia Widiasarana Indonesia: Jakarta.

[9] Wirodikro, H. (2009). Prinsip-Prinsip Statistik untuk Teknik dan Sains. Penerbit Erlangga: Jakarta.

[10] A, Frank., Tillman., T, Deandra., dan Cassone. (2012). A Professional's Guide To Decision Science And Problem Solving. FT Press : United States of America 